\title{
Prophylactic negative pressure wound dressing (NPWD) after caesarean - an extended debate to include surgical aspects
}

Shashikant Sholapurkar ${ }^{1}$

${ }^{1}$ Royal United Hospital NHS Trust

August 4, 2021

\section{Letter to the Editor, BJOG}

Title:Prophylactic negative wound pressure dressing (NWPD) after caesarean - an extended debate to include surgical aspects

Re: Hyldig N, Joergensen JS, Lamont RF, Moller S, Vinter CA. Prophylactic negative pressure wound therapy in obese women undergoing caesarean section: a commentary on new evidence that fuels the debate. BJOG 2021; https://doi.org/10.1111/1471-0528.16750.

Author: Mr. Shashikant L SHOLAPURKAR

$\mathrm{MD}, \mathrm{DNB}, \mathrm{MRCOG}$

Dept of Obstetrics \& Gynaecology,

Royal United Hospital, Bath, BA1 3NG, UK

Email: s.sholapurkar@nhs.net

Tel: 07906620662

Word count: 500

Corresponding Author: Mr. Shashikant L SHOLAPURKAR

MD, DNB, MRCOG

Dept of Obstetrics \& Gynaecology,

Royal United Hospital, Bath, BA1 3NG, UK

Statement of interest: The author has no conflict of interest or funding to declare.

Letter to the Editor (BJOG)

Title: Prophylactic negative pressure wound dressing (NPWD) after caesarean - an extended debate to include surgical aspects

Re: Hyldig N, Joergensen JS, Lamont RF, Moller S, Vinter CA. Prophylactic negative pressure wound therapy in obese women undergoing caesarean section: a commentary on new evidence that fuels the debate. BJOG 2021; https://doi.org/10.1111/1471-0528.16750.

Dear Editor,

The "surgical" issue of caesarean wound infection seems a tussle between opposing biostatisticians. ${ }^{1,2}$ Tuuli et $\mathrm{al}^{2}$ may rightly defend statistical validity of their much larger invaluable RCT showing definitive evidence 
of ineffectiveness of NPWD, contrary to claim. ${ }^{1}$ The major reproducibility/replication crisis in medicine illustrates limitations of our tools/methodologies (not wrong but incomplete). Fred Bookstein, ${ }^{3}$ Professor of Statistics and Life Sciences at Washington and Vienna Universities elucidated principles for drawing conclusions from experimental/trial data - biological plausibility, dose-response relationships, broad evidence (including consilience), adjustments for measurement error and potential confounders and (last/least important) statistical significance. The statistical tests simply cannot prove the actual hypothesis $\left(\mathrm{H}_{1}\right)$ e.g. whether NPWD is effective; which is circumvented by disproving a substitute null-hypothesis $\left(\mathrm{H}_{0}\right) .{ }^{4}$ This can introduce a big difference (e.g. the intriguing prosecutor's fallacy) as the renowned data-scientist from Washington University reiterated that if the original hypothesis is very weak/unlikely; then even if a study shows 'statistical significance', the original hypothesis is still very likely to be false (difference due to chance or confounders). ${ }^{4}$

Are the hypotheses underlying NPWD very weak with misemployment of laboratory research? Application of suction to skin-surface dressing is claimed to bring-in more blood and oxygen but take away the lymph! The last thing pregnant women (higher blood-volume and massive estrogens/progestogens) have is poor vascularity/tissue-hypoxia of abdominal wall, even with high BMI. In contrast, the underlying problems are hematomas, contusion and serosanguinous collections providing nidus for microbes. The shearing movements between the incised adipose layers in overweight women being prevented by superficial NPWD seems unreasonable/unwarranted as opposed to careful suturing technique. Unfortunately, the discussion about good surgical techniques (benefitting low and high BMI women) is unglamorous/unfashionable, summarily rejected as 'anecdotal opinion'. The obstetricians are discouraged from even thinking about the pros-cons of the surgical techniques but simply copy their colleagues.

The author has performed about 150-200 caesareans/year for 35 years with one wound infection in a woman of 68 BMI. This is immaterial or he simply didn't know his patients with wound infection is not a valid argument. Moreover, anyone can achieve $<1 \%$ rate with similar technique. He has specifically avoided application of brute blunt force for abdominal entry. The meme of Joel-Cohen-technique became prematurely entrenched from small trials and got increasingly exaggerated to excessive indiscriminate blunt force of nonsurgical-precision. Such force causes widespread tissue-trauma (unseen beyond the incision), inflammation and hematomas. Paradoxically, more sharp and limited focussed blunt dissection constitute good tissuehandling/surgical-principle. This paradox goes unnoticed; the last thing fish may notice is water. Meticulous abdominal closure is also important. Most of the depth of adipose tissue, particularly in overweight women, should be approximated by robust interrupted layer/s of sutures to minimize shearing movements. Placing a fine $(3-5 \mathrm{~mm})$ vacuum-drain above the sheath for a few days in overweight women will drain any exudate (also provide twenty-times cheaper and superior negative pressure).

Prophylactic NPWD seems wastefully expensive and ineffective. Judiciously designed large trials of surgical techniques are required, mindful that same surgeons may not be able to switch between contrasting techniques.

Disclosure of interests: No conflict of interest or funding to declare.

\section{References:}

1. Hyldig N, Joergensen JS, Lamont RF, Moller S, Vinter CA. Prophylactic negative pressure wound therapy in obese women undergoing caesarean section: a commentary on new evidence that fuels the debate. BJOG 2021; https://doi.org/10.1111/1471-0528.16750.

2. Tuuli MG, Liu J, Tita ATN, Longo S, Trudell A, Carter EB, et al. Effect of Prophylactic Negative Pressure Wound Therapy vs Standard Wound Dressing on Surgical-Site Infection in Obese Women After Cesarean Delivery: A Randomized Clinical Trial. JAMA. 2020;324(12):1180-1189.

3. Bookstein FL. Measuring and Reasoning: Numerical Inferences in the Sciences. $1^{\text {st }}$ ed. Cambridge, UK: Cambridge University Press; 2014.

4. Bergstrom CT, West JD. The susceptibility of Science. In: Bergstrom CT, West JD. Calling BullshitThe Art of Scepticism in a Data-Driven World. 1st ed. London, UK: Allen Lane, Penguin Random 
House; 2020. p. 206-241. 